\title{
China, Children, Homes, Health (CCHH)
}

Asthma and allergies have been increasing worldwide during the last 5 decades. Fifty years ago, prevalences of asthma and allergies were less than $1 \%$; compared to today when up to $1 / 3$ of children in some regions have been diagnosed with asthma. The burden on families and the health care system is great. The increase in asthma, rhinitis, and eczema (whether atopic or not) among children has been demonstrated by the numerous ISAAC studies (International Study on Asthma and Allergies in Children) [1,2]. In some recent studies, the increase has been found to slow or even reverse in some countries.

In spite of a large interest from medical and environmental sciences (ambient air), reasons for the increase in allergic diseases are not clear. It is acknowledged that the increase cannot be due to genetic changes, as the time period is too short. Instead it appears that environmental changes are responsible. But what environmental changes? Outdoor air has, in most western countries, been radically improved during the time that asthma and allergy prevalences have increased [3]. The "hygiene Hypothesis" holds that the environment today is "too clean": children are not exposed to dirt, as they once were, so that the immune system has too little to do, and starts reacting to pollen, cat allergen and other allergens instead of to pathological microbes. However, as of this writing (March 2013) there are 179 reviews of the scientific literature on the "hygiene hypothesis" and the general conclusion is that it cannot explain the increase (or decrease) in these diseases or specific allergies, see e.g. [4]. The food hypothesis, a variant on the hygiene hypothesis, holds that changes in food and preparing food have caused changes in intestinal microbial flora in a way that facilitates the development of asthma and allergies. However, no evidence has emerged, even from large scale studies, that changes in food or drink are a major cause. Several other hypotheses have been offered and discussed. The most common is that the increase might simply be due to medical practitioners being updated so that they diagnose these diseases more often. However, many studies have shown an increase in symptom prevalence greater than that of doctors' diagnoses. Several risk factors have been identified, including exposure to environmental tobacco smoke (ETS) or pets, lack of breastfeeding, caesarian delivery, but no single risk factor can explain the rapid increase. Nonetheless, the cause must be something that has changed in our environment.

Exposure (inhalation, ingestion) to indoor air is by far the largest (by mass) that humans experience, especially during early childhood. The home accounts for more than $50 \%$ of the exposure during life, and for about $75 \%$ during infancy. There have been dramatic changes both qualitatively and quantitatively in indoor air exposure during the last decades, namely, more energy efficient buildings leading to less ventilation; new building and furnishing materials, and new consumer products.

In 2000, Swedish researchers started an extended study of small children on both the prevalences of asthma and allergies, and risk factors in the home environment in Sweden-The first author of this editorial is one of the leading researchers. Then, such research continued in Bulgaria, Singapore, USA (Texas), South Korea, Denmark. We now continue that in mainland of China. Phase I consists of cross-sectional studies to estimate prevalences as well as risk and protective factors; and Phase II compares the home environments of sick and healthy (normal) children in case-control studies. Phase II has been performed in Sweden, Bulgaria, Singapore and Denmark.

The main findings thus far are that risk factors include genetic disposition (family history of allergy and/or asthma), presence of "modern" chemicals in the home, and a lack of ventilation. Findings differ slightly between countries and regions, and among the cities reported on in this special topic. The strongest risk factors for asthma in small children have been identified in Sweden as certain phthalates and glycol ethers [5,6]. These new chemical compounds are used in "modern life" products such as plastics, water based paints, hygiene products, toys and skin lotion and have been detected in high concentrations in home environments. Many of these chemicals are also endocrine disruptors (EDCs) that have health outcomes in addition to asthma and allergy [7].

Accordingly, "modern" health effects like asthma, may be due to "modern" exposures, rather than to a lack of "old exposures" like dirt, microbes, mold nanoparticles or $\mathrm{PM}_{2.5}$, entities which have always been in our environment, but which can now be measured. There were no plasticizers 60 years ago, but today, exposure to such "modern" materials is inescapable.

Initially, asthma and allergy prevalences mainly increased in western developed countries with high GDP/capita countries (e.g. western Europe) but not in countries with lower GDP/capita (e.g. eastern Europe). Today many developing countries have a high prevalence of asthma, so perhaps it is not how rich a society is, but what "modern" exposures they have.

As a developing country with the most population in the world, China is experiencing a most rapid and dramatic change in indoor environment exposures due to rapid modernization and urbanization [8]. Indicators of are presented in Figure 1 (building area; production of synthetic wood, plasticizer, and air conditioners) [9-15]. 


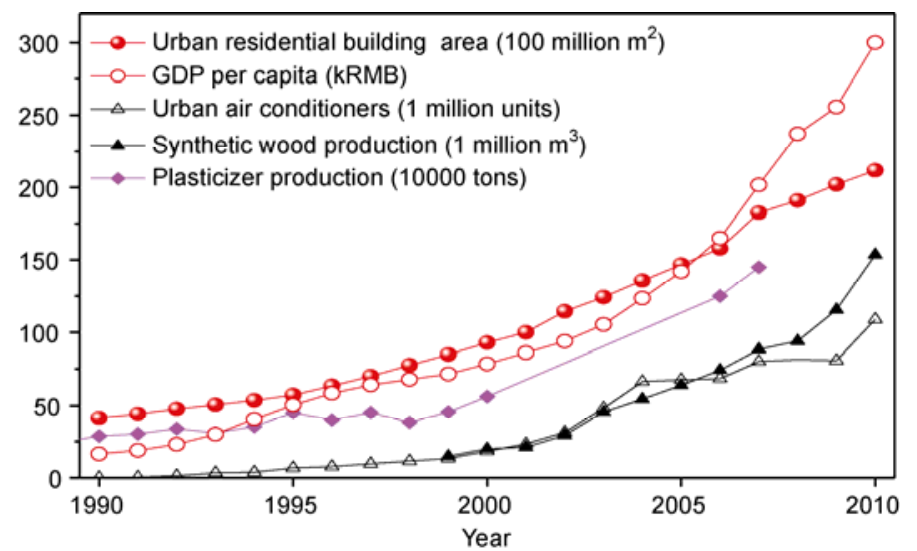

Figure 1 Indicators of rapid modernization in China during the period 1990-2010. For this figure, we have extracted 3 curves from [8].

In China, up to 2000 the prevalence of asthma was 1\%-2\% [16], but there were indications that it was rapidly increasing [17]. So what are the specific Chinese risk factors?

At a 2010 meeting in Chongqing we decided to conduct a Phase I study on the home environment and prevalences of asthma and allergies in China. The overall project was named CCHH (China, Children, Homes, Health) and Phase I has now been performed in Beijing, Chongqing, Changsha, Shanghai, Wuhan, Harbin, Nanjing, Taiyuan, Xi'an and Urumqi. The questionnaire from the earlier asthma and home environment studies was used, with home environment questions modified to better represent Chinese cultural and housing characteristics.

The preliminary findings from Phase I are presented in this special topic. Twelve of the thirteen articles report those from individual cities, and one article integrates and summarizes the data and the findings regarding disease prevalence, building and life style factors from the 10 cities. Individual city articles deal with different aspects of disease and exposures:

From Beijing: possible protective effect of breastfeeding against asthma and allergy [18];

From Shanghai: risks associated with exposure to pets [19] and risks associated with ETS [20];

From Wuhan: risk factors in the home environment associated with asthma and rhinitis [21] and risk factors in the home environment associated with eczema [22];

From Nanjing: family and home environmental risk factors for pneumonia [23];

From Urumqi: home environmental risk factors for pneumonia, wheezing and rhinitis symptoms [24];

From Taiyuan: association of prenatal exposure to new furniture and home decorations with wheeze, rhinitis and eczema [25];

From Changsha: association between ambient air pollution and health [26];

From Chongqing: association between dampness and asthma/allergies [27] and prevalence of and risk factors for sick building syndrome [28];

From Xi'an: association between the home environment and life style on children's health [29].

Risk factors for all health effects include dampness, new furniture and home decorations, living close to heavy traffic, pets, and maternal smoking. Generally protective factors include breastfeeding, frequent cleaning, and frequent putting bed linen to sunshine.

Asthma prevalences were found to vary between 1.3\% (Taiyuan) to 9.8\% (Shanghai) in Chinese big cities. This means that the prevalence in developed regions of China now is the same as in many western countries. Prevalences are lower in less developed areas of China, suggesting "modernity" and "western life" as risk factors. Phase II will further investigate risk factors.

The findings presented in this special topic raise important questions.

(1) Asthma and allergies are increasing in China. What are the specific causes? New furniture, remodeling, dampness, lack of ventilation, ambient air pollution, less breastfeeding?

(2) The incidence of pneumonia is high. Pneumonia is linked to e.g. burning of biomass for cooking in rural settings, but these children live in modern apartments.

(3) Sick Building Syndrome (SBS) symptoms among parents are common, and are linked to the same risk factors as children diseases. Is there a link between parents' SBS and children's atopic or non-atopic diseases?

The results in this special topic show that asthma, allergies, as well as some infectious diseases are important in China. What to do? A lot of more research is needed. But we can also follow the example from Sweden, where national wide campaigns were made 1995 “The Allergy Year”, and 1999 “The Indoor Climate Year”, by the Swedish National Institute of Pub- 
lic Health. These campaigns have seemingly meant that these diseases are relatively less common in Sweden compared to similar countries.

1 Asher M I, Montefort S, Bjorksten B, et al. Worldwide time trends in the prevalence of symptoms of asthma, allergic rhinoconjunctivitis, and eczema in childhood: ISAAC Phases One and Three repeat multicountry cross-sectional surveys. Lancet, 2006, 368: 733-743

2 Asher M I. Recent perspectives on global epidemiology of asthma in childhood. Allergol Immunopath, 2010, 38: 83-87

3 Anderson H R, Ruggles R, Pandey K D, et al. Ambient particulate pollution and the world-wide prevalence of asthma, rhinoconjunctivitis and eczema in children: Phase One of the International Study of Asthma and Allergies in Childhood (ISAAC). Occup Environ Med, 2010, 67: 293-300

4 Brooks C, Pearce N, Douwes J. The hygiene hypothesis in allergy and asthma: An update. Curr Opin Allergy Clin Immunol, 2013, 13: 70-77

5 Bornehag C G, Sundell J, Weschler C J, et al. The association between asthma and allergic symptoms in children and phthalates in house dust: A nested case-control study. Environ Health Perspect, 2004, 112: 1393-1397

6 Choi H, Schmidbauer N, Sundell J, et al. Common household chemicals and the allergy risks in pre-school age children. PLoS One, 2010, 10: e13423

7 Bergman Å, Heindel J J, Jobling S, et al. State of the science of endocrine disrupting chemicals-2012. United Nations Environment Programme (UNEP) and World Health Organization (WHO), 2013

8 Zhang Y P, Mo J H, Weschler C J. Reducing health risks from indoor exposures in today's rapidly developing urban China. Environ Health Perspect, 2013, 121: 751-755

9 Jin Y L. Production situation and prospect of domestic and foreign plasticizer (in Chinese). Chemical Industry Times, 1993, 5: 10-16

10 Yu L P, Gao G H. Situation and development of domestic plasticizer industry (in Chinese). Techno-Econom Petrochem, 1997, 13: 26-30

11 Yu X X. Analysis of plasticizer market (in Chinese). Adv Fine Petrochem, 2002, 3: 24-27

12 Tao G, Liang C. Analysis on development tendency of domestic and global plasticizer market (in Chinese). Plast Sci Technol, 2008, 36: 78-81

13 Wang L, Zhao B, Liu C, et al. Indoor SVOC pollution in China: A review. Chin Sci Bull, 2010, 55: 1469-1478

14 China Forestry Development Report (in Chinese). State Forestry Administration of China. 2000-2011

15 China Statistical Yearbook (in Chinese). National Bureau of Statistics of China. http://www.stats.gov.cn/tjgb/.2012

16 National Cooperation Group on Childhood Asthma of China. Comparative analysis of the state of asthma prevalence in children from two nation-wide surveys in 1990 and 2000 (in Chinese). Chinese Journal of Tuberculosis and Respiratory Diseases, 2004, 27: 112-116

17 Bai J A, Zhao J, Shen K L, et al. Current trends of the prevalence of childhood asthma in three Chinese cities: A multicenter epidemiological survey. Biomed Environ Sci, 2010, 23: 453-457

18 Qu F, Weschler L B, Sundell J, et al. Increasing prevalence of asthma and allergy in Beijing pre-school children: Is exclusive breastfeeding for more than 6 months protective? Chin Sci Bull, 2013, 58: 4190-4202

19 Huang C, Hu Y, Liu W, et al. Pet-keeping and its impact on asthma and allergies among preschool children in Shanghai, China. Chin Sci Bull, 2013, 58: $4203-4210$

20 Liu W, Huang $\mathrm{C}, \mathrm{Hu} \mathrm{Y}$, et al. Associations between indoor environmental smoke and respiratory symptoms among preschool children in Shanghai, China. Chin Sci Bull, 2013, 58: 4211-4216

21 Zhang M, Wu Y, Yuan Y, et al. Effects of home environment and lifestyles on prevalence of atopic eczema among children in Wuhan area of China. Chin Sci Bull, 2013, 58: 4217-4222

22 Zhang M, Zhou E S, Ye X, et al. Indoor environmental quality and the prevalence of childhood asthma and rhinitis in Wuhan area of China. Chin Sci Bull, 2013, 58: 4223-4229

23 Zheng X H, Qiang H, Zhao Y L, et al. Home risk factors for childhood pneumonia in Nanjing, China. Chin Sci Bull, 2013, 58: 4230-4236

24 Wang T T, Zhao Z H, Yao H, et al. Housing characteristics and indoor environment in relation to children's asthma, allergic diseases and pneumonia in Urumqi, China. Chin Sci Bull, 2013, 58: 4237-4244

25 Zhao Z H, Zhang X, Liu R R, et al. Prenatal and early life home environment exposure in relation to preschool children's asthma, allergic rhinitis and eczema in Taiyuan, China. Chin Sci Bull, 2013, 58: 4245-4251

26 Lu C, Deng Q H, Ou C Y, et al. Effects of ambient air pollution on allergic rhinitis among preschool children in Changsha, China. Chin Sci Bull, 2013, 58: 4252-4258

27 Wang H, Li B Z, Yang Q, et al. Dampness in dwellings and its associations with asthma and allergies among children in Chongqing: A cross-sectional study. Chin Sci Bull, 2013, 58: 4259-4266

28 Wang J, Li B Z, Yang Q, et al. Sick building syndrome among parents of preschool children in relation to home environment in Chongqing, China. Chin Sci Bull, 2013, 58: 4267-4276

29 Sun Y, Li A G, Liu Z, et al. The influence of home environmental factors and life style on children's health in Xi'an. Chin Sci Bull, 2013, doi: $10.1007 / \mathrm{s} 11434-013-6087-5$

Guest editors: SUNDELL Jan ${ }^{1}$, LI BaiZhan ${ }^{2}$ \& ZHANG YinPing ${ }^{1}$

${ }^{1}$ Department of Building Science, Tsinghua University, Beijing 100084, China;

${ }^{2}$ School of Urban Construction \& Environment Engineering, Chongqing University, Chongqing 400045, China

Open Access This article is distributed under the terms of the Creative Commons Attribution License which permits any use, distribution, and reproduction in any medium, provided the original author(s) and source are credited. 